\title{
Sławomir Augusiewicz
}

\section{ZAŁOGA PISZA W LATACH 1656-1658}

Słowa kluczowe: $\quad$ Pisz, pułkownik Dietrich von Lessgewang, druga wojna północna

Schlüsselwörter: Johannisburg (Pisz), Oberst Dietrich von Lessgewang, Zweiter Nordischer Krieg

Keywords: Pisz (former Johannisburg), colonel Dietrich von Lessgewang, Second Northern War

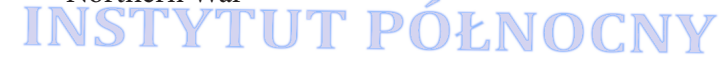

Na temat obsady twierdzy piskiej w XVII wieku literatura historyczna w zasadzie milczy. Dotychczas nieco uwagi poświęcono tylko fortyfikacjom, choć analizowano raczej aspekty urbanistyczne, niż militarne planów systemu umocnień z drugiej połowie XVII stulecia ${ }^{1}$. Również proces budowy nowożytnych założeń obronnych wokół Pisza nie został jak dotąd należycie zbadany, jedynie Bogusław Dybaś $^{2}$ przy okazji publikacji projektów twierdzy z początku XVII wieku zebrał i usystematyzował informacje, zawarte także w syntezach dziejów miasta i zamku³, oraz wprowadził nowe informacje zdobyte w wyniku kwerendy archiwalnej. O załodze wojskowej Pisza najobszerniej wspomniał Emil Johannes Guttzeit, twierdząc, że stanowiły ją kolejno: kompania dragonów pod porucznikiem Aleksandrem Borowskim w 1644 roku, kompania kapitana Hektora von Losch w 1655 roku i kompania piechoty z regimentu Syburga w 1656 roku$^{4}$. Pominął przy tym powtarzaną przez innych autorów informację Georga Christopha Pisanskiego, jakoby w lutym

1 S. Herbst, Plan Pisza z kręgu Narońskiego (polski przyczynek do zagadnienia ,miasta idealnego"), Komunikaty Mazursko-Warmińskie, 1962, nr 3, ss. 620-622; T. Zarębska, Początki polskiego piśmiennictwa urbanistycznego, Warszawa-Łodź 1986, ss. 323-326

2 B. Dybaś, Koncepcja ufortyfikowania Pisza z początku XVII wieku, przyczynek do projektowania nowożytnej twierdzy bastionowej, Komunikaty Mazursko-Warmińskie, 1995 nr 4, ss. 343-349.

3 G.Ch. Pisanski, Collectanea zu einer Beschreibung der Stadt Johannisburg in Preusen, Mitteilungen der Litterarischen Gesellschaft Masovia, Heft 8, 1902, ss. 59-108; J. Maciejewska, Z dziejów zamku krzyżackiego w Piszu, Komunikaty Mazursko-Warmińskie, 1960, nr 2, ss. 235-246; J. Maciejewska, Rozwój przestrzenny Pisza, Komunikaty Mazursko-Warmińskie, 1962, nr 2, ss. 397-416; Pisz. Z dziejów miasta i powiatu, red. W. Korycka, Olsztyn 1970, ss. 142-147; A. Boetticher, Die Bau- und Kunstdenkmaler der Provinz Ostpreusen. Heft 6: Masuren, Koenigsberg 1896, ss. 48-49.

4 E.J. Guttzeit, Der Kreis Johannisburg. Ein ostpreußisches Heimatbuch, Würzburg 1964, s. 308. 
1657, podczas ataku wojsk litewskich na Prusy Książęce, komendantem twierdzy był podpułkownik Grumkow, a załogę stanowiły dwie kompanie piechoty, ponadto w mieście stacjonowały dwie kompanie rajtarii podpułkownika Bernharda Friedrich von Arnim ${ }^{5}$. Choć przekazy źródłowe potwierdzają w niektórych przypadkach pobyt wymienionych jednostek w Piszu, to jednak nadinterpretacją wydaje się przypisywanie im funkcji załogi twierdzy. Przeprowadzone badania pozwoliły zweryfikować powyższe informacje, ustalić okres powstania kompanii przeznaczonej do obsadzenie twierdzy piskiej, jej liczebności i składu osobowego.

W pierwszej połowie XVII stulecia w Prusach Książęcych tylko Kłajpeda, Piława i Królewiec posiadały stałe garnizony ${ }^{6}$. W nadgranicznych zamkach przebywali jedynie puszkarze i wachmistrze, nadzorujący tamtejsze cekhauzy (zbrojownie), ich personel i kilku zaciężnych knechtów ${ }^{7}$ W Piszu u schyłku XVI wieku znajdowało się dwóch puszkarzy, ale prowadzący pod koniec 1586 roku inspekcję zamku generalny zbrojmistrz Księstwa Hans Schrimpf proponował, aby ze względu na jego położenie w pobliżu granicy, przysłać tu jeszcze jednego z Królewca ${ }^{8}$. Nie wiadomo czy zamysł ten został zrealizowany, dwa lata później ten sam Schrimpf donosil nadradcom pruskim ogólnie o puszkarzach piskich, którzy skarżyli się na zbyt niskie uposażenie, ale nie podał ich liczby9.

W następnych latach obsada zamku zapewne się nie zmieniała. Położenie Pisza na szlaku z północnego Mazowsza i Podlasia na Królewiec zadecydowało wprawdzie o wyznaczeniu mu ważnej roli w systemie obrony kraju i włączeniu do projektów tworzenia systemu fortyfikacyjnego w latach 1602 i $1618^{10}$, ale do 1647 roku ostatecznie utworzono co najwyżej wały ziemno-drewniane wokół starego zamku, nie obejmujące miasta ${ }^{11}$. Nie było więc też potrzeby tworzenia specjalnej

G.Ch. Pisanski, Collectanea, s. 95; G.Ch. Pisanski, Nachricht von dem im Jahre 1656 geschehenen Einfall der Tartaren nach Preussen, Mitteilungen der Literarische Gesellschaft Masovia, H. 7, 1901, s. 109; M. Toeppen, Historia Mazur, wyd. G. Jasiński, Olsztyn 1995, s. 229; J. Maciejewska, Z dziejow zamku krzyżackiego w Piszu, s. 245.

6 S. Augusiewicz, Przebudowa wojska pruskiego. U źródeł wczesnonowożytnej armii, Oświęcim 2014, ss. 95, 98, 103-104. Tamże wykaz źródeł i literatury. Zob. także: S. Augusiewicz, Załoga Piławy w 1601 roku. Skład i organizacja, w: Studia nad staropolską sztuką wojenną, t. IV, red. Z. Hundert, K. Żojdź, J.J. Sowa, Oświęcim 2015, ss. $243-257$.

7 C. Jany, Geschichte der Preußischen Armee vom 15. Jahrhundert bis 1914, Bd. I, Von den Anfänge bis 1740, Osnabrück 1967, s. 27; C. Krollmann, Das Defensionswerk im Herzogtum Preussen, Teil I, Die Begründung des Defensionswerks unter dem Markgrafen Georg Friedrich und dem Kurfürsten Joachim Friedrich, Berlin 1904, s. 57-58, 80. S. Augusiewicz, Przebudowa wojska pruskiego, s. 92.

8 Hansen Schrimpfen Haubtmans zur Mummel bedencken wegen bestellunge der Grenzheuser mit Geschutz, Buchsmeisetr und ander Munition, GStAPK, I HA, Rep. 7 (Preussen), nr 94, nlb; [Hans Schrimpf], Relation wegen gehaltenen umbzugen und besichtigung der Grenz und Zeughauses, bmd, ibidem.

9 Hansen Schrimpfen general zeugmeisters Bercht wegen der Johannßburgischen Büchsenmeister [1588], GStAPK, I HA, Rep. 7 (Preussen), nr 97, k. 4-4v; nadradcy pruscy do księcia Jerzego Fryderyka, Königsberg 4 X 1588, ibidem, k. 18-18v.

10 S. Augusiewicz, Przebudowa wojska pruskiego, ss. 91-92, 104-105; B. Dybaś, op. cit., ss. 343-349.

11 O takim zakresie prac fortyfikacyjnych, prowadzonego po 1628 roku wg projektu inżyniera Christiana Rose, jest mowa w liście Friedricha von Lehndorff do elektora Jerzego Wilhelma, Pisz 12 IV 1635, GStAPK, XX 
załogi. Do tego celu organizowano najczęściej oddziały zaciężne w kraju lub wykorzystywano tego typu jednostki przybyłe z Brandenburgii. Stany pruskie z reguły sprzeciwiały się pobytowi w Księstwie tego typu jednostek. Nawet w chwilach największego zagrożenia, jakim była wojna polsko-szwedzka w Prusach Królewskich w latach 1626-1629, werbunki były bardzo ograniczone ${ }^{12}$. Do obsadzenia położonych w rejonie konfliktu zamków na południowo-zachodnim odcinku granicy Księstwa (Szczytnie, Nidzicy i Działdowie) oraz Piławy i Kłajpedy, wykorzystano wtedy, a także w latach trzydziestych, kiedy groziło wznowienie działań wojennych po wygaśnięciu rozejmu altmarskiego, brandenburskie oddziały zaciężne ${ }^{13}$. Wątpliwe, by wymieniona wyżej kompania Borowskiego faktycznie stanowiła załogę Pisza w 1644 roku. Porucznik Aleksander von Borowski rzeczywiście dowodził w tym czasie kompanią dragonów, ale nie zaciężną, lecz utworzoną z chłopów z dóbr książęcych (Wybranzen) starostwa piskiego ${ }^{14}$, czyli formacją o charakterze milicyjnym, z jakich składała się wówczas pruska obrona krajowa. Mobilizowano je sporadycznie na popis i ćwiczenia lub w wypádku zagrożenia kraju ${ }^{15}$. Jedyne znane źródło, w którym Borowski został wymieniony jako dowódca kompanii dragonów starostwa piskiego to rejestr oficerów obrony krajowej sporządzony wg ordynacji w kwietniu 1644 roku, którzy mieli zostać zaprzysiężeniu w Królewcu. Nie ma w nim mowy o dyslokacji jednostek ${ }^{16}$.

Faktycznie natomiast w Piszu znalazły się dwie kompanie z regimentu piechoty Arnima, ale nie w 1655, jak twierdzi Guttzeit, lecz wcześniej, w 1649 roku. Nie powierzono im też żadnych zadań związanych z obroną twierdzy, żołnierzom tych jednostek przydzielono jedynie kwatery (stacje) w mieście. Berndt Friedrich von Arnim dowodził utworzonym w Brandenburgii z 4 kompanii skwadronem piechoty, przerzuconym do Prus Książęcych na przełomie sierpnia i września 1648

HA, EM 57k, nr 15, k. 4. Zob. także: B. Dybaś, Collectanea, s. 344; G.Ch. Pisanski, op. cit., s. 63; J. Maciejewska, Z dziejów zamku krzyżackiego w Piszu, s. 239

12 S. Augusiewicz, Przebudowa wojska pruskiego, ss. 76-78.

13 O. Zimmermann, Das Defensionswerk im Herzogtum Preußen unter dem Kurfürsten Georg Wilhelm, Königsberg 1933, s. 97.

14 G.A. Mülversdtedt, Die brandenburgische Kriegsmacht unter dem Grossen Kurfürsten, Magdeburg 1888, s. 500; C. Jany, Geschichte der Preußischen Armee, s. 112; R. Courbiere l'Homme, Geschichte der brandenburgisch preussischen Heeresverfassung, Berlin 1852, s. U. Marwitz, Staatsräson und Landesdefension. Untersuchungen zum Kriegswesens des Herzogtums Preußen 1640-1655, Boppard am Rein 1984, s. 186; S. Augusiewicz, Przebudowa wojska pruskiego, s. 75 .

15 C. Krollmann, Das Defensionswerk im Herzogtum Preussen, Teil I, passim; C. Krollmann, Das Defensionswerk im Herzogtum Preussen, Teil II, Das Defensionswerk unter dem Kurfürsten Johann Sigismund, Berlin 1909, passim; O. Zimmermann, op. cit., passim; C. Jany, Geschichte der Preußischen Armee, ss. 26-30; J. Petersohn, Die Landesdefeniosn im Herzogtum Preusßen zu Beginn des 17. Jahrhunderts, Zeitschrift für Ostforschungen, Jhrg. X, 1961, H. 2, ss. 226-237; U. Marwitz, op. cit. passim; S. Augusiewicz, Przebudowa wojska pruskiego, ss. 19-91.

16 „4[-te Compagnie] Johanneßburgk führet ietzo Alexander Borowfsky alß ein Leutenant“, Austeilung der 4 Compagnien Dragoner nach des H. Obristen Belieben volgents Anzuordnen GStAPK, XX HA, EM 111k, nr 97, k. 24v; Landmiliz des Herzogthums Preußen, A. Liste vom Jahre 1644, w: G.A. Mülversdtedt, op. cit., ss. 711-712. 
roku, a wycofanym we wrześniu $1650^{17}$. Jesienią 1648 roku skwadron został zakwaterowany (nie rozdzielony na załogi) w miastach leżących na południu kraju. W Piszu od 25 grudnia 1648 do 26 stycznia 1649 znajdowała się kompania kapitana Caspara Sieberta (Syberta) von Cronenfels (115 żołnierzy), potem przerzucona do Rynu i Szczytna. W jej miejsce do miasta przybyła kompania kapitana Johanna Casimira von Moll (Möhlen) (również 115 żołnierzy). 12 lutego 1649 część kompanii została przeniesiona do Ełku, pozostali żołnierze opuścili Pisz 6 lipca ${ }^{18}$.

Zapewne twierdza została po raz pierwszy obsadzona stałym wojskiem zaciężnym dopiero po wybuchu wojny polsko-szwedzkiej, kiedy Prusom Książęcym jesienią 1655 zagrażał atak wojsk szwedzkich.. Ukończono już wtedy rozpoczętą w 1647 roku budowę rozległych, bastionowych fortyfikacji, okalających zamek i miasto ${ }^{19}$. Przekazy z tego okresu nie potwierdzają jednak obecności kompanii dragonów kapitana Hectora von Losch w twierdzy. Losch rzeczywiście był wówczas dowódcą tej jednostki, utworzonej z wybrańców ze starostwa piskiego, zastąil, zapewne po 1650 roku, wspomnianego wyżej Borowskiego ${ }^{20}$. Wymienia go rejestr jednostek obrony krajowej i ich oficerów (Tabelle der Generalaufgebote), ale bez podania dyslokacji, sporządzony po ogłoszeniu przez Fryderyka Wilhelma 2 września 1655 roku mobilizacji służb rycerskich i wybrańców w Księstwie ${ }^{21}$.

Komendantem twierdzy w okresie wojny 1655-1660 nie był także, w ogóle zresztą w niej nie był, Stephan Christian von Grumbkov (Grumbkau, Grumkow). Przynajmniej od lutego 1656 dowodził on regimentem dragońskim Christiana Ludwiga von Kalckstein ${ }^{22}$. Po przystąpieniu Fryderyka Wilehlma do wojny przeciw Rzeczypospolitej i wkroczeniu sprzymierzonych ze Szwedami wojsk brandenburskich do Polski regiment obsadził Łęczycę. 4 października 1656, po odzyskaniu tego miasta przez wojska Jana Kazimierza Grumbkov dostał się do niewoli. Wkrótce został z niej wraz z innymi oficerami zwolniony i już w listopadzie przebywał w Prusach Książęcych, ale nie w Piszu, lecz w Labiawie. Do sierpnia 1657 roku otrzymywał żołd, jednak nie dowodził już żadną jednostką ${ }^{23}$. W lutym 1657 roku

17 C. Jany, Geschichte der Preußischen Armee, s. 111; U. Marwitz, op. cit., s. 38-39; S. Augusiewicz, Przebudowa wojska pruskiego, ss. 89-90.

18 Liquidation zwischen S.C. Ambtern, Städten und H.Obristen Leutenandt Bernd Friderich von Arenheim, 5. und .6 8ber 1649, GStAPK, XX HA, OsF 827, k. 312-312v.

19 Fortyfikacje zaprojektował inżynier Gerorg Treber: Abriß des Schloßes Johannisburg 1647.Georg Treber E.F. Bestaller u. Geschworner Landt. Messer u. Ingenuer, denn 4 Martius Ao 1647“, GStAPK, XX HA, EM 57a, nr 9, k. 1.Ludwig von Kannacher do Fryderyka Wilhelma, Pisz 26 II 1647, GStAPK, XX HA, EM 58k, nr 1, k. 4-5; Georg Treber do elektora Fryderyka Wilhelma, Pisz bd [przed 3 VIII 1647], GStAPK, OsF 12658, k. 126; B. Dybaś, op. cit., s. 344; U Marwitz, op. cit., ss. 57-62.

20 U. Marwitz, op. cit., s. 186.

${ }^{21}$ GStAPK, XX HA, EM 83m, nr 36; GStAPK, XX HA, EM 83a nr 26, k. 44-45; GStAPK, XX HA, HBA, K6, Kasten 1385, k. 41-42; Landmiliz des Herzogthums Preußen, A. Liste vom Jahre 1644, G.A. Mülversdtedt, op. cit., ss. 712-715.

22 Preussischer General-Kriegs-Etats von 1 Februar 1656 bis letzten September 1657, GStAPK, XX HA, OsF 831, k. 194-197.

23 GStAPK, XX HA, OsF 830/1, k. 22v; GStAPK, XX HA, OsF 830/5, k. 16v; GStAPK, XX HA, OsF 830/6, 
znajdował się za to w Piszu podpułkownik Christian von Zastrov, były dowódca regimentu rajtarii, który także jesienią 1656 dostał się do niewoli polskiej, lecz wkrótce wykupiony z niej powrócił do Księstwa ${ }^{24}$. Jednak również i on nie dowodził wówczas załogą Pisza.

Regularne, zaciężne jednostki wojskowe zostały po pierwszy wprowadzone do twierdzy piskiej najpóźniej w październiku 1655 roku, kiedy generał Georg Friedrich von Waldeck przygotowywał obronę wschodniej i południowo-wschodniej granicy Prus Książęcych przed spodziewanym atakiem wojsk szwedzkich z Inflant i Litwy ${ }^{25}$. Pułkownik Heinrich von Wallenrodt w raporcie do Waldecka z 9 listopada wymienia komendanta twierdzy podpułkownika Wetzel ${ }^{26}$. Musiała więc w Piszu znajdować się wówczas załoga, ale brak informacji o jej składzie i liczebności. Wspomniany komendant był zapewne tożsamy z pochodzącym z Nowej Marchii Georgiem Wetzel, który już przed 1643 rokiem służył w armii szwedzkiej, ale opuścił ją po wybuchu wojny polsko-szwedzkiej ${ }^{27}$. Oberstem (szefem) własnej jednostki (regimentu piechoty) został dopiero wiosną $1656^{28}$

25 lutego 1656 roku kapitulację na werbunek kompanii złożonej ze 100 „Teutscher Knechte”, przeznaczonej na stałą załogę Pisza („Diese Compagnie soll stets auff dem Hause Johannisburg verbleiben"), otrzymał pułkownik Dietrich von Lessgewang 29 . Starsze opracowania niemieckie wymieniają Lessgewanga jako rotmistrza w armii brandenburskiej już w $1640 \mathrm{roku}^{30}$, bogate doświadczenia wojskowe zdobył jednak przede wszystkim w służbie polskiej. W 1646 roku był majorem w regimencie dragońskim swojego brata Johanna Albrechta w armii koronnej ${ }^{31}$, a od 1652 roku dowodził tam już jako pułkownik własnym regimentem rajtarskim ${ }^{32}$. Do Prus Książęcych wrócił na przełomie sierpnia i września 1655 roku, wkrótce

k. 16v, 38; GStAPK, XX HA, OsF 830/7, k. 64; GStAPK, XX HA, OsF 831, k. 194-194v, 380-381v; Der officirer von der Kalcksteinschen Esquadron Dragoner, so von Lenschitz zurück gekommen und und anitzo lhier vorhanden, GStAPK, XX HA, OsF 830/6, k. 160.

${ }^{24}$ GStAPK, XX HA, OsF 831, k. 382-383; G.A. Mülverstedt, op. cit., s. 491; C. Jany, Geschichte der PreuBischen Armee, s. 131; S. Augusiewicz, Przebudowa wojska pruskiego, ss. 172, 215.

25 S. Augusiewicz, Przebudowa wojska pruskiego, ss. 157-160.

26 H. von Wallenrodt do G.F. Waldecka, Drigan 9 XI 1655, Urkunden und Acktenstücke zur Geschichte des Kurfüsten Friedrich Wilhelm von Brandenburg, Bd. VII, hrsg. B. Erdmannsdörffer, Berlin 1877, s. 477.

27 A.B. König, Biographisches Lexicon aller Helden und Militairpersonen, welche sich in preußischen Diensten berühmt gemacht haben, Teil 4, Berlin 1791, ss. 213-214; G.A. Mülverstedt, op. cit., ss. 488-489.

28 C. Jany, Die alte Armee von 1655 bis 1740 : (Formation und Stärke), Urkundliche Beiträge und Forschungen zur Geschichte des Preußischen Heeres, Bd. 2, Heft 7, Berlin 1906, s. 8;

29 GStAPK, XX HA, EM 83e, nr 52, k. 20; GStAPK, XX HA, I HA, Rep. 24, Lit. K, fasc. 25, k. k. 19-20; C. Jany, Die alte Armee von 1655 bis 1740, s. 7; C. Jany, Geschichte der Preußischen Armee, s. 134; G.A. Mülverstedt, op. cit., s. 316; S. Augusiewicz, Przebudowa wojska pruskiego, ss. 186-187.

30 G.A. Mülverstedt, op. cit., s. 315.

31 S. Augusiewicz, Przebudowa wojska pruskiego, ss. 84-85, tamże wykaz źródeł i literatury.

32 J. Wimmer, Materiały do zagadnienia organizacji i liczebności armii koronnej w latach 1648-1655, Studia i Materiały do Historii Wojskowości, t. V, 1960, ss. 477-486. Zachował się rejestr popisowy tej jednostki: AGAD, Archiwum Skarbu Koronnego dz. 85, nr 73, ss. 271-278. 
otrzymał kapitulację na werbunek 4 kompanii do regimentu rajtarii i nominację na starostwo piskie z rekomendacji nadradców pruskich ${ }^{33}$. W czerwcu 1656 roku regiment rajtarii Lessgewanga został przekazany Heinrichowi von Kalnein ${ }^{34}$, być może wiązało się to z powierzeniem pułkownikowi funkcji komendanta twierdzy piskiej. Nie zachowała się jednak nominacja, w żadnym źródle nie był też tak tytułowany. Kierował jednak obroną Pisza podczas ataku wojsk litewsko-polsko-tatarskich pod wodzą hetmana Wincentego Gosiewskiego w październiku 1656 roku³5.

Formowanie kompanii piechoty Lessgewanga zakończyło się zapewne w czerwcu 1656 roku, pierwszy rejestr popisowy jednostki nie jest datowany ${ }^{36}$. Żołd przyznano kompanii od lipca $1656^{37}$, więc popis musiał się odbyć na początku tego miesiąca lub pod koniec poprzedniego. Jej organizacja była typowa dla brandenburskich oddziałów pieszych tego okresu. Na czele kompanii stał sztab (prima plana) złożony z oficerów, podoficerów i personelu (19 osób), żołnierze podzieleni byli na 17 rot (gefrajter i 5 szeregowych, razem 102). W następnych miesiącach stan ten się zmieniał (zob. tabela 1). Lessgewang był nominalnie Oberstem (szefem) jednostki, ale faktyczną komendę sprawował major Hans Georg von Hohendorff. Hohendorff jako kapitan dowodził kompanią w formowanym w Prusach Książęcych od lipca 1648 roku regimencie piechoty Christopha von Houwaldt ${ }^{38}$, który w latach 1649-1652 służył w armii koronnej i walczył przeciw Kozakom i Tatarom na Ukrainie (bitwy pod Zborowem, Beresteczkiem i Batohem) ${ }^{39}$.

Po przystąpieniu elektora Fryderyka Wilhelma do wojny przeciw Rzeczypospolitej po stronie Szwecji (przymierze w Malborku 25 czerwca 1656) konieczne stało się wzmocnienie obrony granicy wschodniej i południowej Prus Książęcych. Kompania Lessgewanga mogła okazać się niewystarczająca do obrony twierdzy w przypadku zagrożenia, tym bardziej że była jednostką świeżo utworzoną, złożo-

33 An S.Churfl.Dhl zu Brandenburg nomine der Herren Regiments Rähte. Dieterich von Leßgewang Obrister wird zum Hauptman nach Johannisburg vorgeschlagen, den 7 Septembris Anno 1655 GStAPK, XX HA, EM 57b, nr 6, k. 1-1v; Die Dessauer Stammliste von 1729, hrsg. C. Jany, Urkundliche Beiträge und Forschungen zur Geschichte des Preußischen Heeres, H. 8, Berlin 1905, s. 114; S. Augusiewicz, Przebudowa wojska pruskiego, ss. $130-131$.

34 GStAPK, XX HA, OsF 831, k. 73-79, 115v; GStAPK, XX HA, 830/1, k. 12; S. Augusiewicz, Przebudowa wojska pruskiego, s. 183

35 D. Lessgewang do Fryderyka Wilhelma, Johannisburg 15 X 1656, GStAPK, XX HA, OsF 829, k. 501, 510. Listy opublikował K.A. Maczkowski, Beiträge zur Geschichte des zweiten schwedisch-polnischen Krieges (1655660) un der Tatareneinfälle in Preussen (1656 und 1657), Mitteilungen der Literarische Gesellschaft Masovia, H.6, 1900, ss. 13-14 133-153v.

36 Rolla der Frey Compagnia auf dem Grentz Hauße Johannißburg, bmd, GStAPK, XX HA, OsF 830/2, k.

37 GStAPK, XX HA, OsF 830/1, k. 49; GStAPK, XX HA, OsF 831, k. 319-323.

38 Kriegshändel und Kosten der Durchzüge und Quartiere dess Hertzogthumb Preussen von Herrn General Major Houwald, Herr Obr. Leutnants Arnibs und H. Rittmeister Brandten Völcker von Jahren 1648, 1649 und 1650, GStAPK, XX HA, OsF 827, k. 887-891.

39 J. Wimmer, Materiały do zagadnienia organizacji i liczebności armii koronnej w latach 1648-1655, nlb 
ną $\mathrm{w}$ większości, jak można wnosić $\mathrm{z}$ rejestru popisowego, z miejscowych chłopów, nie mających doświadczeń służby wojskowej. Zapewne dlatego w czerwcu 1656 roku do twierdzy skierowano dodatkowo kompanię piechoty kapitana Burhardta Schultza z regimentu Kaspara von Siegberga (Syburga), która stacjonowała tam przynajmniej do końca grudnia 1656 roku $^{40}$. Dodatkowa kompania, kapitana Johanna von Brausfeldt $\mathrm{z}$ tego samego regimentu piechoty Siegberga, wzmacniała załogę piską także w okresie od lipca do września 1657 roku $^{41}$.

Kompania Lessgewanga została wycofana $\mathrm{z}$ Pisza jesienią 1658 roku i skierowana do Królewca ${ }^{42}$, kiedy po kolejnej reorientacji polityki brandenburskiej (traktaty z Rzecząpospolitą zawarte jesienią 1657 roku) konieczne stało się wzmocnienie obrony północnych rejonów Prus Książęcych, zagrożonych desantem morskim i ze strony zgrupowań szwedzkich w Prusach Królewskich i Inflantach. W lipcu 1660, w wyniku redukcji armii brandenbursko-pruskiej, zarządzonej przez Fryderyka Wilhelma po zawarciu pokoju oliwskiego kończącego wojnę ze Szwecja, kompania została rozwiązana, a oficerowie i żołnierze wcieleni do kompanii przybocznej ówczesnego namiestnika Prus Książęcych Bogusława Radziwiłła ${ }^{43}$.

Poniżej zamieszczono tabelę ilustrującą liczebność kompaníi Lessgewanga W całym okresie jej istnienia. Źródłem do jej sporządzenia były księgi Generalnego Komisariatu Wojennego ${ }^{44}$ (Kriegs Etats (...) über seiner Churfürstl. Durchl. zu Brandenburg in dero Hertzogthumb Preussen stehenden Armee), zawierających ewidencję jednostek wojskowych, rozliczenia wypłat żołdu i zaopatrzenia za poszczególne miesiące. Kriegs Etats zawiera także dane dotyczące liczebności jednostek (sztabu i żołnierzy szeregowych). Formalnie kalkulacja kosztów jej utrzymania powinna być sporządzona w oparciu o rejestr (rolle), spisany podczas popisu, niekiedy przeprowadzonego pod koniec miesiąca poprzedzającego miesiąc rozliczeniowy. Jeśli faktycznie wymóg taki został spełniony, w Kriegs Etats zamieszczano rzeczywisty stan

40 GStAPK, XX HA, OsF 831, k. 267-268; GStAPK, XX HA, OsF 830/2, k. 28, 72-75; GStAPK, XX HA, OsF 830/3, k. 24v; GStAPK, XX HA, OsF 830/4, k. 26, 112-115; GStAPK, XX HA, OsF 830/7, k. 51v-53v, 371-387.

41 GStAPK, XX HA, OsF 831, k. 269; GStAPK, XX HA, OsF 838/5, k. 42, 347-350; GStAPK, XX HA, OsF 838/6, k. 33v; GStAPK, XX HA, OsF 831, k. 269. G. A. Mülverstedt (op. cit., s. 442) twierdzi, że w Piszu znajdowała się wtedy także kompania z regimentu piechoty Otto Christopha von Sparr, jednak nie potwierdzają tego materiały pruskiego Koisariatu Wojennego, według których cały regiment brał w tym czasie udział w kampanii na północnym Mazowszu, GStAPK, XX HA, OsF 838/5, k. 56-60; S. Augusiewicz, Działania wojsk brandenburskich na pótnocno - wschodnim Mazowszu i Podlasiu wiosna i latem 1657 roku, Studia i Materiały do Historii Wojskowości, t. XLIII, Białystok 2007, ss. 83-86.

42 G.A. Mülverstedt, op. cit., s. 316

43 Rozporządzenie Fryderyka Wilhelma do Bogusława Radziwiłła, Cölln a.d. Spree, 2 VI 1660, GStAPK, XX HA, OsF 1251, k. 154; S. Augusiewicz, Materiały do zagadnienia polityki elektora brandenburskiego Fryderyka Wilhelma wobec stałego wojska w Prusach Książęcych po pokoju oliwskim 1660 roku, Mrągowskie Studia Humanistyczne, t. IV - V, 2002/2003, s. 166; GStAPK, XX HA, OsF 834, k. 291; C. Jany, Die alte Armee von 1655 bis 1740 , s. 11; Die Dessauer Stammliste von 1729, s. 98; G.A. Mülverstedt, op. cit., s. 316.

44 Organ administracji wojskowej z kompetencjami w zakresie kwaterunków, aprowizacji i finansowania armii, S. Augusiewicz, Przebudowa wojska pruskiego, ss. 178-181, tamże wykaz literatury. 
osobowy jednostki, choć zdarzało się, że przyznawano mniejszą liczbę stawek żołdu, niż wynikałoby to z rejestru popisowego. Jeśli jednostka nie przeprowadziła popisu, Komisariat wojenny kalkulację żołdu opierał o dane z ostatniego rejestru lub wg pełnego stanu, określonego w kapitulacji na werbunek jednostki. Wspomniana wyżej kapitulacja, którą otrzymał Lessgewang, określała liczebność jednostki na 100 żołnierzy szeregowych bez sztabu, który w kompaniach piechoty liczył z reguły 18 oficerów, podoficerów i personelu. W niektórych przypadkach Komisariat przyznawał żołd tylko dla żołnierzy szeregowych. W zamieszczonej niżej tabeli zaznaczono, które dane pochodzą z rejestrów popisowych, a więc odpowiadają stanowi faktycznemu, oraz przypadki rozbieżności między rejestrem a liczbą stawek żołdu przyznanych przez Komisariat.

Zamieszczono również skład osobowy kompanii w ramach jej struktury organizacyjnej, opracowany na podstawie rejestrów popisowych z lipca, października i listopada 1656 oraz kwietnia 1658 roku. W pierwszym wykazie zaznaczono zmiany personalne, które zaszły w poszczegỏlnych miesiącach. Zachowano oryginalną pisownią imion i nazwisk, odnotowując $\mathrm{w}$ nawiasie różnice występujące w poszczególnych rejestrach. Stopnie i funkcje wojskowe podano stosując, zgodnie z najnowszą propozycją Jerzego Maronia, polskie odpowiedniki ${ }^{45}$.

Tabela 1. Liczebność kompanii piechoty pułkownika Dietricha von Lessgewang w okresie od lipca 1656 do końca maja 1660

\begin{tabular}{|l|c|c|c|c|c|c|c|c|c|c|}
\hline \multirow{2}{*}{} & \multicolumn{2}{|c|}{1656} & \multicolumn{2}{c|}{1657} & \multicolumn{2}{c|}{1658} & \multicolumn{2}{c|}{1659} & \multicolumn{2}{c|}{1660} \\
\cline { 2 - 11 } & 1 & 2 & 1 & 2 & 1 & 2 & 1 & 2 & 1 & 2 \\
\hline styczeń & & & & & $13^{\text {ae }}$ & $93^{\mathrm{a}}$ & 17 & 80 & & $120^{\mathrm{a}}$ \\
\hline luty & & & $16^{\text {ad }}$ & $90^{\mathrm{a}}$ & 13 & 93 & 17 & 80 & & 120 \\
\hline marzec & & & $20^{\mathrm{a}}$ & $92^{\mathrm{a}}$ & $13^{\mathrm{ae}}$ & $83^{\mathrm{a}}$ & & 108 & & 120 \\
\hline kwiecień & & & 20 & 92 & $13^{\mathrm{ae}}$ & $81^{\mathrm{a}}$ & & $110^{\mathrm{a}}$ & & 100 \\
\hline maj & & & $18^{\text {ad }}$ & $90^{\mathrm{a}}$ & $13^{\mathrm{ae}}$ & $81^{\mathrm{a}}$ & & 100 & & 100 \\
\hline Czerwiec & & & 20 & 100 & $13^{\mathrm{ae}}$ & $81^{\mathrm{a}}$ & & 110 & & \\
\hline lipiec & $19^{\mathrm{ab}}$ & $102^{\mathrm{a}}$ & 20 & 100 & $13^{\mathrm{a}}$ & $72^{\mathrm{a}}$ & & 110 & & \\
\hline sierpień & 19 & 102 & 20 & 100 & $13^{\mathrm{ae}}$ & $75^{\mathrm{a}}$ & & 110 & & \\
\hline wrzesień & $20^{\mathrm{a}}$ & $99^{\mathrm{a}}$ & 20 & 100 & 16 & 73 & & 110 & & \\
\hline październik & $20^{\mathrm{a}}$ & $108^{\mathrm{a}}$ & & 100 & 16 & 73 & & $120^{\mathrm{a}}$ & & \\
\hline
\end{tabular}

45 J. Maroń, O stopniach i stanowiskach wojskowych doby wczesnonowożytnej słów kilka, w: Między Lwowem a Wrocławiem. Ksiega Jubileuszowa Profesora Krystyna Matwijowskiego, red. B. Rok, J. Maroń, Toruń 2006, ss. 1101-1109. 


\begin{tabular}{|l|c|c|c|c|c|c|c|c|c|c|}
\hline & \multicolumn{2}{|c|}{1656} & \multicolumn{2}{c|}{1657} & \multicolumn{2}{c|}{1658} & \multicolumn{2}{c|}{1659} & \multicolumn{2}{c|}{1660} \\
\cline { 2 - 12 } & 1 & 2 & 1 & 2 & 1 & 2 & 1 & 2 & 1 & 2 \\
\hline listopad & 20 & 108 & & 100 & 16 & 73 & & 120 & & \\
\hline grudzień & $18^{\mathrm{ac}}$ & $102^{\mathrm{a}}$ & 13 & 100 & $17^{\mathrm{a}}$ & $78^{\mathrm{a}}$ & & 120 & & \\
\hline
\end{tabular}
a. stan wg rejestru popisowego (rolli);
b. rejestr popisowy wykazuje 20 osób sztabu;
c. rejestr popisowy wykazuje 20 osób sztabu; popis przeprowadzono 20 XI 1656;
d. rejestr popisowy wykazuje 20 osób sztabu;
e. rejestr popisowy wykazuje 18 osób sztabu;
1 - liczebność sztabu kompanii; 2 - żołnierzy szeregowych

Źródło: GStAPK, XX HA, OsF: 830/2, k. 40, 133-136v; 830/3, k. 39v; OsF 830/4, k. 35, 172-176; 830/5, k. 39v, 211 - 214; 830/6, k. 33; 830/7, k. 55, $401-404 ; 831$, k. $319-323 ; 838 / 1$, k. 32, $191-194 ; 838 / 2$, k. $200-203 ; 838 / 3$, k. $36,150-153 ; 838 / 4$, k. 36, 187 - 190; 838/5, k. 43v; 838/6, k. 34v; 838/7, k. 17; 838/8, k. 18v; 839/1, k. 20, 193 - 196; 839/2, k. 19, 52; 839/3, k. 20, 67 - 70; 839/4, k. 19, $79-82 ; 839 / 5$, k. 18v, 77 - 80; 839/6, k. 18v, $103-105$; $839 / 7$, k. 22v, 248 - 250; 839/8, k. 20v, 109 - 112; 839/9, k. 23, $96-99 ; 840 / 1$, k. 28; 840/2, k. 23v, 84 - 87; 840/3, k. $26840 / 4$, k. $27 \mathrm{v} ; 840 / 5$, k. 22; 840/6, k. $23840 / 7$, k. 23; 840/8, k. 25, 55 - 57; 840/9, k. 26; 841, k. 23, 122, 557; $842 / 1$, k. 27v, 101-102; 842/2, k. 26; 842/3, k. 23; 842/4, k. 23v; 842/5, k. 23v; 833, k. 19, 27v, 57v, 107, 150, 195, $240,290 \mathrm{v}, 348 \mathrm{v}, 410 \mathrm{v}, 450 \mathrm{v}, 491 \mathrm{v}, 530 \mathrm{v}, 570 \mathrm{v}, 612 ; 834, \mathrm{k} .283-291$; Extract der alhier im Hertzogthumb Preussen stehenden Churbrandenburgichen Infanterie, wie selbe in letzgehaltener Musterung gemäß eingegebnen Rollen bestanden und befunden worden, 1658, GStAPK, XX HA, EM 83e, nr 52, k. 38v-39; S. Augusiewicz, Przebudowa wojska pruskiego, s. 323.

\section{Skład kompanii piechoty Dietricha von Lessgewang w Piszu od lipca do listopada $1656^{46}$}

Sztab kompanii (prima Plana) major Hannß Georg von Hondorff porucznik Christian Reinhardt chorąży Hannß Heinrich von Bromserd adiutnat Hannß Terner sierżant Tobiaß Grube sierżant Jacob Fendera sierżant Gregor Olschefsky gefrajter kapral Andreß Menicke kapitanarmus (zbrojmistrz) Steffan Hacke furier Hannß Geißlr pisarz Hannß Casper, w październiku Merten Grim, w listopadzie Hannß Loffer felczer Baltzer Hendel, w październiku Baltzer Braun, w listopadzie Baltzer Hendel

46 Rolla der Frey Compagnia auf dem Grentz Hauße Johannißburg, bd [lipiec 1656], GStAPK XX HA, OsF 830/2, k. 133-135v; Rolla der Frey Compagnia auf dem Grentz Hause Johannißburgk [Johanßburg 22 X 1656], GStAPK, XX HA, OsF 830/5, k. 211v-213v; Rolla der Frey Compagnia auf dem Grentz Hause Johannißb. [Johanßburg 20 XI 1656], GStAPK, XX HA, OsF 830/7, k. 402-404. 
kapral Wilhelm von Knöbel

kapral Hannß Kusienofsky

kapral Georg Erdman

dobosz Hannß Bocda (Bockda)

dobosz Jacob Strencka

dobosz Wentzel Terner

flecista (piszczek) Jacob Blaß

stępka Hannß Ham

Pierwsza rota:

gefrajter Jochim Dehn

Hannß Schmied

Jacob Mück

Hannß Klehn, w listopadzie Albrecht Mietzech

Albrecht Gromatziegk

Andreß, Waldaw

Druga rota:

gefrajter Mertten Marschunßky

Hannß Melcher

Hannß Pietzko

Georg Skarinßky

Siemon Kurschniers

Michel Heldt

Trzecia rota

gefrajter Andreß Güntter

Gregor Stellmacher

Michel Miotzech

Andres Fielborn, w październiku i listopadzie Albrecht Nieckoleitzig

Mathes Kollodzey

Hannß Frisch, w październiku i listopadzie Jan Mendroßigk (Hannß Mendrofsky)

Czwarta rota:

gefrajter Fridrich Ripp

Siemon Baderofsky

Andreß Bergaw, w listopadzie Stentzel Schiemansich

Mertten Koch 
Paul Olschefsky

Siemon Grube, w październiku Peter Jazinßky, w listopadzie Egmond Johan

Piąta rota:

gefrajter Hannß Norck

Michel Gurny

Hannß Munck, w październiku i listopadzie Thomas Smiggorowka (Smiggarofsky)

Barttel Barantzigk

Jacob Wieschnefsky

Paul Laetzigk (Lätzech)

Szósta rota:

gefrajter Hannß Klingbiettel

Paul Androßzich, w październiku i listopadzie Baltzer Borckofsky

Barttel Voydt, w październiku i listopadzie Hánnß Görietzen

Jacob Kerpofzieg

Albrecht Gregorzieg

Heinrich Gromey, w październiku i listopadzie Albrecht Scheitziegk

Siódma rota:

gefrajter Fridrich Borckerdt

Albrecht Gudziegk

Christoff Krohl, w listopadzie Lorentz Saleßka

Hannß Kulcka

Mathes Laetzig

Albrecht Schelinßky, w październiku i listopadzie Hannß Georg Schkarlach

Ósma rota:

gefrajter Jochim Farinßky

Marttin Konopka

Mathes Freytagk

Michel Kollek, w październiku Casper Lempitzky, w listopadzie Georg Schmide Hannß Steinmeltziegk

Ambrosius Dumoschefsky, w październiku i listopadzie Jacob Prußik z Turowa

Dziewiata rota:

gefrajter Hannß Bodtkommertzieg

Paul Woynofsky 
Andres Guttofsky

Christoff Gordietzieg

Hannß Schelinßky

Hannß Schelaßke, w listopadzie Christoff Machte

Dziesiąta rota:

gefrajter Fabian Lettaw, w listopadzie Michel Federziegk

Marttin Quasta

Baltzer Kriesanofsky

Michel Kriesanofsky

Thomaß Woynofsky

Matheß Pietzko

Jedenasta rota:

gefrajter Gregor Zierkofsky

Erdtman Schiemansich

Joseph Ognifka, w październiku i listopadzie Adam Koßlieg

Christian Gurny

Michél Ließiegk

Hannß Fuchß, w październiku i listopadzie Thomaß Lißkowßky (Lißkowßky)

Dwunasta rota:

gefrajter Hannß Kochsofsky, w październiku i listopadzie Barttel Voytt (Voydt) Georg Dehn

Albrecht Scheitziegk, w październiku i listopadzie Marzin Rakowsky (Marttin Rackofsky)

Hannß Steltziegk

Paul Bellny, w październiku i listopadzie Albrecht Frantzig (Frontzig)

Georg Pupßky

Trzynasta rota:

gefrajter Jacob Poleschnieg

Jacob Rieback

Adam Moyschefsky

Michel Odtwosich

Albrecht Liepinßky

Jacob Weßel 
Czternasta rota

gefrajter Hannß Georg Friedrich

Andreß Ziebarofsky

Mathes Suba, w październiku i listopadzie Adam Konopzieg

Albrecht Kruschefsky

Jacob Nieschitka

Hannß Graboßich (Grabosich)

Piętnasta rota

gefrajter Vallten Thiel, w październiku Siemon Grube, listopadzie Albrecht Hanweyser

Hannß Ternner, w październiku i listopadzie Adam Januschzieg

Martin Bergk, w październiku i listopadzie Woyteck Raphelzieg

Michel Quetzschny, w październiku i listopadzie Jan Sdunzieg

Michel Soldtziegk, w październiku i listopadzie Michel Jendtkowßky (Jentkofsky)

Gregor Kollitzschigk (Kollidziegk)

Szesnasta rota:

gefrajter Georg Lieschefsky, w październiku i listopadzie Albrecht Schelinßky

Hannß Salescha, w październiku Michel Sadtzieg, w listopadzie Michel Laetzigk

Albrecht Kuschzach, w październiku Albrecht Hanweyser, w listopadzie Jacob

Weyde

Matheß Mehtlock

Michel Stanofa, w październiku i listopadzie Hannß Ladda

Michel Macher, w październiku i listopadzie Michel Zeßny

Siedemnasta rota:

gefrajter Albrecht Koschelziegk, w październiku i listopadzie Ambrosius Dumoschefsky

Paul Bursigk, w październiku Michel Laetzigk, w listopadzie Hanß Thomeck Hannß Wiersach, w październiku Jacob Weide, w listopadzie Friedrich Schwartz Jacob Pogorefsky, w październiku i listopadzie Frantz Westphal

Tobiaß Underman, w pażdzierniku Hannß Madt, w listopadzie Hannß Ternner Barttel Fanduer, w październiku Michel Berzugk, w listopadzie Michel Ließkowsky

Osiemnasta rota tylko (istniała tylko w październiku)

gefrajter Hannß Skrotzky

Tobias Underman 
Michel Ließkofsky (w XI 1656 w siedemnastej rocie)

Friedrich Schwartz (w XI 1656 w siedemnastej rocie)

Marttin Sadowßky

Hannß Salescha

Skład kompanii piechoty Dietricha von Lessgewang w Piszu, kwiecień $1658^{47}$

Sztab kompanii (prima Plana)

major Hanß Georg von Hohendorff

porucznik Erasmus Christoff von Arnswaldt

chorąży Balthasar Friedrich von Hohendorff

adiutant Hanß Terner

sierżant Tobias Grubell

sierżant Andreas Meinicke

sierżant Wilhelm von Knebell

gefrajter kapral Hanß Kazanowski

kapitanarmus (zbrojmistrz) Joachim Dehn

furierHanß Georg Friedrich

pisarz Martin Spitting

felczer Christian Hoyerus

kapral Hanß Norcke

kapral Hanß Kuzanowsky

kapral Friedrich Ripp

dobosz Hanß Bogda

dobosz Jacob Schrencka

stępka Hanß Hanim

Pierwsza rota:

gefrajter AndreasWaldau

Merten Solkoll

Jacob Creisla

Michel Moitzig

Tomas Shmigarowsky

JacobWischnewsky

47 Rolla über des Herren Obristen Dietrich von Leßgewang Frey Compagnie auff den Monat Ano 1658 Aprilis, [Johanßburg 5 IV 1658], GStAPK, XX HA, OsF 839/4, k. 79-81v. 
Druga rota:

gefrajter Hanß Klingbiel

Jacob Albrecht

Michel Owzig

Andreas Kugglick

Hans Kulka

Jacob Sögling

Trzecia rota:

gefrajter Hanß Kuglick

Michel Heldt

Caspar Domanowsky

Michel Sobolewsky

Merten Konopka

Stentzel Kolinowsky

Ertman Shimantzigk

Czwarta rota:

gefrajter Jacob Ribback

Georg Ertman

Albrecht Kruschowsky

Andreas Storch

Merten Poßpech

Piąta rota:

gefrajter Matheas Pietzka

Jacob Nishitka

Michel Skrysanowsky

Andreas Felborzu

Merten Krüger

Matheas Kolzig

Szósta rota:

gefrajter Hans Graboszeig

Hanß Wulff

Jacob Wilbach

Jacob Kerpowsky

Hanß Marcirig 
Jacob Wessell

Siódma rota:

gefrajter Michel Odwosig

Georg Skarsinsky

Christoff Mierzig

Hanß Tomaschrig

Friedrich Borhert

Merten Criernewsky

Ósma rota:

gefrajter Jacob Meyer

Jacob Ochatz

Paul Woynowsky

Jacob Podlesznio

Merten Calischrig

Thomas Bembeniak

Dziewiąta rota:

gefrajter Friedrich Wahrendorff

Stas Lucas

Merten Kakowsky

Hans Podkomorrig

Christoff Stenkewitz

Adam Köslig

Dziesiąta rota:

gefrajter Hanß Baumgardt

Andreas Wischnewsky

Stanislaw Malinowsky

Hans Dudeck

Balthasar Skrysanowsky

Jacob Battschman

Jedenasta rota:

gefrajter Mathes Schwenzitzky

Paul Jendriszrig

Hans Thomas 
Merten Piorka

Christoff Schach

Hanß Stoßig

Dwunasta rota

gefrajter Michel Polennigic

Albrecht Boll

Albrecht Hering

Jacob Gilweg

Andreas Dibowsky

Merten Machowsky

\section{Trzynasta rota:}

gefrajter Hanß Shrotzky

Michel Liskowsky

Christoff Salesky

Merten Karmasin

Fabian Lettaw

\section{Czternasta rota:}

gefrajter Tobias Steuman

Georg Sommer

Hanß Hew

Simon Kowalowsky

\section{Sławomir Augusiewicz, Die Besatzung von Johannisburg (Pisz) in den Jahren 1656-1658}

\section{Zusammenfassung}

Im Beitrag wird die Entstehungsgeschichte, Besetzung, Struktur und Truppenstärke der Kompanie des Obersts Dietrich von Lessgewang besprochen, die im Frühling 1656 als Mannschaft der Festung von Johannisburg gebildet wurde. Gleichzeitig wurden die in der Geschichtsliteratur vorhandenen Informationen über andere Truppenteile, die vermeintlich die Besatzung von Johannisburg vor 1655 oder in der Kriegszeit 1655-1660 ausmachten, der Kritik unterzogen. In der Tat gab es vor 1655 in Johannisburg keine feste Besatzung, nur angesichts der Gefährdung durch die Schweden, dann seitens der Polnischen Republik wurden hier vorläufig die Kompanien der Feld-Regimente eingeführt. Die Kompanie von Lessgewang war eigentlich die erste Besatzung von Johannisburg, sie befand sich in der Festung nur bis Herbst 1658, dann wurde sie nach Königsberg versetzt und im Juli 1660 - aufgelöst. 


\section{Sławomir Augusiewicz, The garrison of Pisz (Johannisburg) in 1656-1658}

Summary

The article discusses the origins, composition, organizational structure and size of Colonel Dietrich von Lessgewang's company, which was formed in the spring of 1656 as the garrison of the fortress in Pisz. At the same time, it critically refers to existing information in the historical literature on other military units at Pisz before 1655 or during the war in 1655-1660. Before 1655, Pisz had no permanent garrison, and in response to the Swedish threat, and then from the Commonwealth, a company from the field regiments was temporarily installed there. Lessgewang's company was the first permanent garrison at Pisz, but was only in the fortress until the autumn of 1658. Later it was moved to Königsberg, and in July 1660 it was dissolved

Translated by Aleksander Pluskowski

Dr hab. Sławomir Augusiewicz

Wydział Humanistyczny

Uniwersytet Warmińsko Mazurski w Olsztynie

slawaug@wp.pl

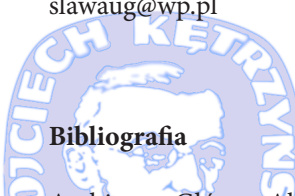

\section{INSTYTUT PÓ\#NOCNY}

Archiwum Główne Akt Dawnych w Warszawie (AGAD)

Archiwum Skarbu Koronnego, dział 85, nr 73;

Geheimes Staatsarchiv Preussischer Kulturbesitz Berlin-Dahlem (GStAPK)

I Hauptabteilung (HA), Rep. 7 (Preussen), nr-y: 94, 97; Rep. 24, Lit. K, fasc. 25;

XX Hauptabteilung: Herzogliches Brief Archiv (HBA), K6, Kasten 1385; Etats Ministerium (EM): 57a, nr 9; 57b, nr 6; 57k, nr 15; 58k, nr 1; 83a, nr 26; 83e, nr 52; 83m, nr 36; EM 111k, nr 97; Ostpreussiche Folianten (OsF), nr-y: $827,829,830,831,833,834,838,839,840,841,842,1251,12658$;

Urkunden und Acktenstücke

1877 Urkunden und Acktenstücke zur Geschichte des Kurfüsten Friedrich Wilhelm von Brandenburg, Bd. VII, hrsg. B. Erdmannsdörffer, Berlin.

Augusiewicz Sławomir

2002/2003 Materiały do zagadnienia polityki elektora brandenburskiego Fryderyka Wilhelma wobec stałego wojska w Prusach Książęcych po pokoju oliwskim 1660 roku, Mrągowskie Studia Humanistyczne, t. IV-V, ss. 158-170.

2007 Działania wojsk brandenburskich na północno - wschodnim Mazowszu i Podlasiu wiosną i latem 1657 roku, Studia i Materiały do Historii Wojskowości, t. XLIII, Białystok, ss. 73-87.

2014 Przebudowa wojska pruskiego. U źródeł wczesnonowożytnej armii, Oświęcim.

2015 Załoga Piławy w 1601 roku. Skład i organizacja, w: Studia nad staropolska sztuką wojenną, t. IV, red. Z. Hundert, K. Żojdź, J. J. Sowa, Oświęcim, ss. 243-257.

Boetticher Adolf

1896 Die Bau- und Kunstdenkmaler der Provinz Ostpreusen. Heft 6: Masuren, Koenigsberg.

Courbiere l'Homme Rene

1852 Geschichte der brandenburgisch - preussischen Heeresverfassung, Berlin.

Die Dessauer Stammliste von 1729

1905 Die Dessauer Stammliste von 1729, hrsg. C. Jany, Urkundliche Beiträge und Forschungen zur Geschichte des Preußischen Heeres, H. 8, Berlin. 
Dybaś Bogusław

1995 Koncepcja ufortyfikowania Pisza z poczatku XVII wieku, przyczynek do projektowania nowożytnej twierdzy bastionowej, Komunikaty Mazursko-Warmińskie, nr 4, ss. 343-349.

Guttzeit Emil Johannes

1964 Der Kreis Johannisburg. Ein ostpreußisches Heimatbuch, Würzburg.

Herbst Stanisław

1962 Plan Pisza z kręgu Narońskiego (polski przyczynek do zagadnienia , miasta idealnego"), Komunikaty Mazursko-Warmińskie, nr 3, ss. 620-622.

Jany Curt

1906 Die alte Armee von 1655 bis 1740: (Formation und Stärke), Urkundliche Beiträge und Forschungen zur Geschichte des Preußischen Heeres, Bd. 2, Heft 7, Berlin.

1967 Geschichte der Preußischen Armee vom 15. Jahrhundert bis 1914, Bd. I, Von den Anfänge bis 1740, Osnabrück.

König Anton Balthasar

1791 Biographisches Lexicon aller Helden und Militairpersonen, welche sich in preußischen Diensten berühmt gemacht haben, Teil 4, Berlin.

Krollmann Christian

1904 Das Defensionswerk im Herzogtum Preussen, Teil I, Die Begründung des Defensionswerks unter dem Markgrafen Georg Friedrich und dem Kurfürsten Joachim Friedrich Berlin

1909 Das Defensionswerk im Herzogtum Preussen, Teil II, Das Defensionswerk unter dem Kurfürsten Johann Sigismund, Berlin.

Maciejewska Joanna

1960 Z dziejów zamku krzyżackiego w Piszu, Komunikaty Mazursko-Warmińskie, nr 2, ss. 235-246.

1962 Rozwój przestrzenny Pisza, Komunikaty Mazursko-Warmińskie, nr 2, ss. 397-416.

Maroń Jerzy

2006 O stopniach i stanowiskach wojskowych doby wczesnonowożytnej słów kilka, w: Między Lwowem a Wrocławiem. Ksiega Jubileuszowa Profesora Krystyna Matwijowskiego, red. B. Rok, J. Maroń, Toruń, ss. 1101-1109.

Marwitz Ulrich

1984 Staatsräson und Landesdefension. Untersuchungen zum Kriegswesens des Herzogtums Preußen 1640-1655, Boppard am Rein.

Maczkowski Karl August

1900 Beiträge zur Geschichte des zweiten schwedisch-polnischen Krieges (1655-660) un der Tatareneinfälle in Preussen (1656 und 1657), Mitteilungen der Literarische Gesellschaft Masovia, H.6, ss. 10-47.

Mülverstedt Georg Adalbert

1888 Die brandenburgische Kriegsmacht unter dem Grossen Kurfürsten, Magdeburg.

Petersohn Jürgen

2961 Die Landesdefenions im Herzogtum Preusßen zu Beginn des 17. Jahrhunderts, Zeitschrift für Ostforschungen, Jhrg. X, H. 2, ss. 226-237.

Pisanski Georg Christoph

1901 Nachricht von dem im Jahre 1656 geschehenen Einfall der Tartaren nach Preussen, Mitteilungen der Literarische Gesellschaft Masovia, H. 7, ss. 87-122. 
1902 Collectanea zu einer Beschreibung der Stadt Johannisburg in Preusen, Mitteilungen der Litterarischen Gesellschaft Masovia, Heft 8, ss. 59-108.

Pisz

1970 Pisz. Z dziejów miasta i powiatu, red. W. Korycka, Olsztyn.

Toeppen Max

1995 Historia Mazur, wyd. G. Jasiński, Olsztyn.

Wimmer Jan

1960 Materiały do zagadnienia organizacji i liczebności armii koronnej w latach 1648-1655, Studia i Materiały do Historii Wojskowości, t. V, ss. 477-486.

Zarębska Teresa

1986 Początki polskiego piśmiennictwa urbanistycznego, Warszawa-Łodź.

Zimmermann Otto

1933 Das Defensionswerk im Herzogtum Preußen unter dem Kurfürsten Georg Wilhelm, Königsberg.

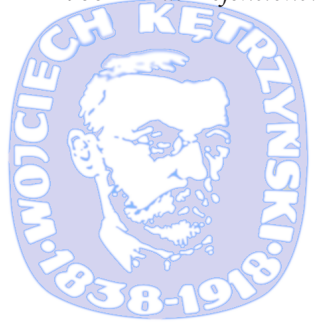

